\title{
Optimal ordering and pricing policy for price sensitive stock-dependent demand under progressive payment scheme
}

\author{
Nita H. Shah ${ }^{\mathrm{a}^{*}}$, Amisha R. Patel ${ }^{\mathrm{b}}$ and Kuo-Ren Lou ${ }^{\mathrm{c}}$
}

${ }^{a}$ Department of Mathematics, Gujarat University, Ahmedabad - 380009, Gujarat, India
${ }^{b}$ U.V.Patel College of Engineering, Ganpat University, Kherva, Mehsana 3840027, Gujarat, India
${ }^{c}$ Department of Management Sciences and Decision Making, Tamkang University, Tanshui, Taipei 251, Taiwan, R.O.C.

\begin{tabular}{|c|c|}
\hline A R T I C L E I N F O & A B S T R A T T \\
\hline $\begin{array}{l}\text { Article history: } \\
\text { Received } 12 \text { January } 2011 \\
\text { Accepted } 21 \text { March } 2011 \\
\text { Available online } \\
22 \text { March } 2011 \\
\text { Keywords: } \\
\text { Inventory } \\
\text { Price-sensitive stock-dependent }\end{array}$ & $\begin{array}{l}\text { The terminal condition of inventory level to be zero at the end of the cycle time adopted by } \\
\text { Soni and Shah (2008, 2009) is not viable when demand is stock-dependent. To rectify this } \\
\text { assumption, we extend their model for (1) an ending - inventory to be non-zero; (2) limited } \\
\text { floor space; (3) a profit maximization model; (4) selling price to be a decision variable, and (5) } \\
\text { units in inventory deteriorate at a constant rate. The algorithm is developed to search for the } \\
\text { optimal decision policy. The working of the proposed model is supported with a numerical } \\
\text { example. Sensitivity analysis is carried out to investigate critical parameters. }\end{array}$ \\
\hline
\end{tabular}

demand

Deterioration

Progressive payment scheme

\section{Introduction}

Levin et al. (1973) quoted that "Large piles of consumer goods displayed in a super market will lead the customers to buy more. Silver and Peterson (1982) also observed that sales at the retail level tend to be proportional to the amount of inventory displayed. Many researchers are engaged in analyzing the relationship between stock-dependent demand and inventory policies. In this direction Baker and Urban (1988) developed an economic order quantity model for a power-form inventory-level dependent demand. Mandal and Phaujdar (1989) formulated a production inventory model when units in inventory are subject to constant rate of deterioration. They considered production to be uniform and stock-dependent demand to be linear. Some more related articles are by Datta and Pal (1990), Giri et al. (1996), Ray and Chaudhuri (1997), Chang et al. (2003, 2006, 2008, and 2010). Some of the above cited articles assumed that the inventory level at the end of the cycle time is zero and objective is to minimize the total cost of an inventory system. Urban (1992) argued that in case of a stock-dependent demand, the terminal condition of zero inventory level may not result in an optimal profit because "it may be advantageous to order larger quantities, resulting in stock left over at the 
end of the cycle, due to the potential profits resulting from the increased demand". For more articles on inventory-level-dependent demand refer to review article by Urban (2005).

In this paper, an ending inventory is taken to be zero or positive. It is assumed that the retailer has limited shelf space and units in inventory are subject to constant rate of deterioration. The profit is maximized with respect to unit sale price and cycle time. The model is validated by a numerical example. The sensitivity analysis is carried out to find out the critical parameters.

\section{Assumptions and notations}

A single-item deterministic inventory model for deteriorating items with price-sensitive stockdependent demand rate is developed with the following assumptions:

1. Shortages are not allowed to avoid lost sales.

2. Replenishment rate is infinite.

3. The lead-time is zero or negligible.

4. The maximal inventory level is $U$ which can be displayed.

5. The initial and ending inventory level may be zero or positive. For repeated replenishment cycle, we assume that the initial and ending inventory levels are the same.

6. The constant fraction of the on - hand inventory deteriorates per unit of time and there is no repair or replacement of the deteriorated inventory.

7. The demand rate, $R(p, I(t))$ is a function of instantaneous stock - level $I(t)$ and selling price, $p$. The functional form of demand function is given by

$R(p, I(t))=(\alpha+\beta I(t)) p^{-\eta}, \quad 0 \leq t \leq T$

where $\alpha, \beta>0$ and $\eta>1$ is mark-up elasticity.

8. If the retailer pays by $M$, then the supplier does not charge any interest to the retailer. If the retailer pays after $M$ and before $N(N>M)$, then the supplier charges the retailer an interest rate of $I_{c 1} /$ unit/year for unsold items. If the retailer pays after $\mathrm{N}$, then the supplier charges the retailer an interest rate of $I_{c 2}$ /unit/year $\left(I_{c 2}>I_{c 1}\right)$ on the remaining stock.

In addition, the following notations are used in the development of the proposed model.

\section{Notation:}

$h$ the inventory holding cost / unit / year

$p \quad$ the selling price / unit (a decision variable)

$c$ the unit purchase cost, with $c<p$

A the ordering cost per order

$M \quad$ the first allowable credit period in settling the account without any interest charges

$N \quad$ the second allowable credit period in settling the account with interest charge $I_{c 1}$ on unpaid dues and $N>M$

$I_{c 1}$ the interest charged per $\$$ in stock per year by the supplier when retailer pays during $[M, N]$

$I_{c 2}$ the interest charged per $\$$ in stock per year by the supplier when retailer pays during

$$
[N, T], \quad I_{c 2}>I_{c 1}
$$

$I_{e} \quad$ the interest earned / \$ / year during $[0, M]$

$T$ the replenishment cycle time in years (a decision variable)

$q \quad$ the inventory level at time $T$ (a decision variable)

$Q \quad$ the inventory level at time $t=0$

$U \quad$ the maximum inventory level 
In next section, we develop the optimal pricing-ordering inventory model for price-sensitive demand under progressive payment scenario.

\section{Mathematical model}

The cycle starts with an order of $Q-q$ units in the inventory system. Since the previous cycle ended with $q$ - units, the initial inventory level (i.e. at $t=0$ ) is $Q$ units. The inventory level gradually depletes to $q-$ units (with $q \geq 0$ ) at time $t=T$ due to deterioration and price-sensitive stock-dependent demand. The rate of change of inventory level at any instant of time is governed by the following differential equation:

$\frac{d I(t)}{d t}+\theta I(t)=-(\alpha+\beta I(t)) p^{-\eta}, \quad 0 \leq t \leq T$

with the boundary condition $I(T)=q \geq 0$. Solving Eq. (2), the on-hand inventory at any instant of time $t$ is given by

$I(t)=\left(q+\frac{\alpha p^{-\eta}}{w}\right) e^{w(T-t)}-\frac{\alpha p^{-\eta}}{w} \quad, \quad 0 \leq t \leq T \quad$ where $\quad w=\theta+\beta p^{-\eta}$

Since $I(0)=Q$, we have

$Q=\left(q+\frac{\alpha p^{-\eta}}{w}\right) e^{w T}-\frac{\alpha p^{-\eta}}{w} \leq U$

The total profit per time unit is generated revenue + interest earned - purchasing cost - ordering cost - inventory holding cost - interest charged (depending upon lengths of the cycle time and allowable credit periods). The generated revenue is $G R=p \int_{0}^{T} R(p, t) d t$, the purchase cost is $P C=c(Q-q)$, the inventory holding cost is $H C=h \int_{0}^{T} I(t) d t$ and the ordering cost per cycle is $O C=A$. Interest earned and interest charged depends upon the length of the cycle time and allowable trade credits $M$ and $N$. Following three cases arise: (1) $T \leq M$, (2) $M<T<N$, (3) $T \geq N$.

\section{1. $T \leq M$}

Here, the replenishment cycle time ends before the first allowable credit period so that interest charged per cycle is $I C_{1}=0$, and interest earned per cycle is

$I E_{1}=p I_{e}\left[\int_{0}^{T} t R(p, t) d t+(M-T) \int_{0}^{T} R(p, t) d t\right]$. In this case, the buyer's annual total profit per time unit is

$Z_{1}(p, T, q)=\frac{1}{T}\left[G R+I E_{1}-P C-H C-O C-I C_{1}\right]$.

\section{2. $M<T<N$}

In this case, during $[0, M]$, the retailer earns interest and is given by $I E_{2}=p I_{e} \int_{0}^{M} t R(p, t) d t$ and during $[M, T]$, he pays interest at the rate $I_{c 1} / \$$ / annum on the unsold stock, i.e. $I C_{2}=c I_{C 1} \int_{M}^{T} I(t) d t$. 
The buyer's annual total profit per time unit is

$Z_{2}(p, T, q)=\frac{1}{T}\left[G R+I E_{2}-P C-H C-O C-I C_{2}\right]$.

\section{3. $T \geq N$}

In this case, interest earned per cycle is $I E_{3}=I E_{2}$. The interest paid by the retailer during $[M, T]$ is given by $I C_{3}=c I_{C 1} \int_{M}^{N} I(t) d t+c I_{C 2} \int_{N}^{T} I(t) d t$. Hence, the buyer's annual total profit per time unit is as follows,

$$
Z_{3}(p, T, q)=\frac{1}{T}\left[G R+I E_{3}-P C-H C-O C-I C_{3}\right]
$$

Thus, the buyer's annual total profit per time unit is as follows:

$$
Z(p, T, q)=\left\{\begin{array}{lc}
Z_{1}(p, T, q) & , \quad 0<T \leq M \\
Z_{2}(p, T, q) & , \quad M<T<N \\
Z_{3}(p, T, q) & , \quad T \geq N
\end{array}\right.
$$

At $T=M, Z_{1}(p, M, q)=Z_{2}(p, M, q)$ and at $T=N, Z_{2}(p, N, q)=Z_{3}(p, N, q)$. Hence, $Z(p, T, q) \Pi(T, q)$ is well - defined continuous function of $T$.

\section{Optimal solution}

To obtain the optimal solution of the proposed problem, we maximize the functions $Z_{1}(p, T, q)$, $Z_{2}(p, T, q)$ and $Z_{3}(p, T, q)$ separately with respect to $p, T$, and $q$, and then compare the results to obtain the optimal value $(p, T, q)$ which maximizes $Z(p, T, q)$. Taking the first order derivatives of $Z_{i}(p, T, q)(i=1,2,3)$ with respect to $p, T$, and $q$, and setting it equal to zero gives

$$
\begin{aligned}
& \frac{\partial Z_{i}(p, T, q)}{\partial p}=0, \\
& \frac{\partial Z_{i}(p, T, q)}{\partial T}=0,
\end{aligned}
$$

and

$$
\frac{\partial Z_{i}(p, T, q)}{\partial q}=0
$$

From Eq. (11), we know $\partial Z_{i}(p, T, q) / \partial q$ is linear in $q$. Hence, 
$\frac{\partial^{2} Z_{i}(p, T, q)}{\partial q^{2}}=0$

Consequently, the sufficiency condition in terms of the Hessian matrix of is

$$
\left(\begin{array}{lll}
\frac{\partial^{2} Z_{i}}{\partial T^{2}} & \frac{\partial^{2} Z_{i}}{\partial T \partial p} & \frac{\partial^{2} Z_{i}}{\partial T \partial q} \\
\frac{\partial^{2} Z_{i}}{\partial p \partial T} & \frac{\partial^{2} Z_{i}}{\partial p^{2}} & \frac{\partial^{2} Z_{i}}{\partial p \partial q} \\
\frac{\partial^{2} Z_{i}}{\partial q \partial T} & \frac{\partial^{2} Z_{i}}{\partial q \partial p} & \frac{\partial^{2} Z_{i}}{\partial q^{2}}
\end{array}\right)=\left(\begin{array}{ccc}
\frac{\partial^{2} Z_{i}}{\partial T^{2}} & \frac{\partial^{2} Z_{i}}{\partial T \partial p} & \frac{\partial^{2} Z_{i}}{\partial T \partial q} \\
\frac{\partial^{2} Z_{i}}{\partial p \partial T} & \frac{\partial^{2} Z_{i}}{\partial p^{2}} & \frac{\partial^{2} Z_{i}}{\partial p \partial q} \\
\frac{\partial^{2} Z_{i}}{\partial q \partial T} & \frac{\partial^{2} Z_{i}}{\partial q \partial p} & 0
\end{array}\right)=\left(\begin{array}{ccc}
\frac{\partial^{2} Z_{i}}{\partial T^{2}} & \frac{\partial^{2} Z_{i}}{\partial T \partial p} \\
\frac{\partial^{2} Z_{i}}{\partial p \partial T} & \frac{\partial^{2} Z_{i}}{\partial p^{2}}
\end{array}\right)<0
$$

From Eq. (11) and Eq. (12), if $\frac{\partial Z_{i}(p, T, q)}{\partial q}>0$, then $Z_{i}(p, T, q)$ is strictly increasing function of $q$. To make $q$ as large as possible, we set $Q=U$ because $q<Q \leq U$. Hence, if $\frac{\partial Z_{i}(p, T, q)}{\partial q}>0$, then $Z_{i}(p, T, q)$ is maximized at $Q=U$. Otherwise, if $\frac{\partial Z_{i}(p, T, q)}{\partial q} \leq 0$, then $Z_{i}(p, T, q)$ is maximized at $q=0$.

Case A. If $\frac{\partial Z_{i}(p, T, q)}{\partial q}>0$, then $Q=U$

Substituting $Q=U$ in Eq. (4), we get

$q=U e^{-w T}-\frac{\alpha p^{-\eta}}{w}\left(1-e^{-w T}\right)$

Substituting Eq. (14) in Eq. (8), the buyer annual total profit function per time unit reduces to a function of two variable, viz. $p$ and $T$.

Case B. If $\frac{\partial Z_{i}(p, T, q)}{\partial q} \leq 0$, then $q=0$.

Substituting $q=0$ in $Z_{i}(p, T, q)(i=1,2,3)$ we get the buyer annual total profit function per time unit to be a function of two variable, viz. $p$ and $T$.

Finally, we compare $Z_{1}\left(p_{1.1}, T_{1.1}, q_{1.1}\right), Z_{1}\left(p_{1.2}, T_{1.2}, q_{1.2}\right), Z_{2}\left(p_{2.1}, T_{2.1}, q_{2.1}\right)$, $Z_{2}\left(p_{2.2}, T_{2.2}, q_{2.2}\right), Z_{3}\left(p_{3.1}, T_{3.1}, q_{3.1}\right), Z_{3}\left(p_{3.2}, T_{3.2}, q_{3.2}\right)$, and then select the optimal solution to the problem as $\left(p^{*}, T^{*}, q^{*}\right), Z\left(p^{*}, T^{*}, q^{*}\right)=\max Z_{i}\left(p_{i, k}, T_{i, k}, q_{i, k}\right), i=1,2,3$, $k=1,2$. 


\section{A computational algorithm}

Step 1. Compute the global maximum of $Z_{1}(p, T, q)$ say $\left(p_{1}^{*}, T_{1}^{*}, q^{*}\right)$ as follows:

Step 1.1 Set $\mathrm{Q}=\mathrm{U}$ and obtain $\left(p_{1.1}, T_{1.1}\right)$ by solving $\frac{\partial Z_{1}(p, T, q)}{\partial p}=0=\frac{\partial Z_{1}(p, T, q)}{\partial T}$. If $T_{1.1} \leq M$ then substitute $p=p_{1.1}$ and $T=T_{1.1}$ into Eq. (14) and use Eq. (5) to evaluate $q_{1.1}$ and $Z_{1}\left(p_{1.1}, T_{1.1}, q_{1.1}\right)$ respectively. Otherwise, set $T_{1.1}=M$ and compute $q_{1.1}$ and $Z_{1}\left(p_{1.1}, T_{1.1}, q_{1.1}\right)$ by using Eq. (14) and Eq. (5), respectively.

Step 1.2 Set $q_{1.2}=0$. Compute $\left(p_{1.2}, T_{1.2}\right)$ by solving $\frac{\partial Z_{1}(p, T)}{\partial p}=0=\frac{\partial Z_{1}(p, T)}{\partial T}$. If $T_{1.2} \leq M$, then obtain $Z_{1}\left(p_{1.2}, T_{1.2}\right)$ from Eq. (5). Otherwise, set $T_{1.2}=M$ and compute $Z_{1}\left(p_{1.2}, T_{1.2}\right)$.

Step 1.3 Find $\left(p_{1}^{*}, T_{1}^{*}, q_{1}^{*}\right), Z\left(p_{1}^{*}, T_{1}^{*}, q_{1}^{*}\right)=\max Z_{i}\left(p_{1 . i}, T_{1 . i}, q_{1 . i}\right), i=1,2$.

Step 2 Find the global maximum of $Z_{2}(p, T, q)$ say $\left(p_{2}^{*}, T_{2}^{*}, q_{2}^{*}\right)$ as follows:

Step 2.1 Set $Q=U$ and compute $\left(p_{2.1}, T_{2.1}\right)$ by solving $\frac{\partial Z_{2}(p, T, q)}{\partial p}=0=\frac{\partial Z_{2}(p, T, q)}{\partial T}$. If $M<T_{2.1}<N$, then substitute $T=T_{2.1}$ into Eq. (14) and Eq. (6) to compute $q_{2.1}$ and $Z_{2}\left(p_{2.1}, T_{2.1}, q_{2.1}\right)$ respectively, If $T_{2.1}<M$, then set $T_{2.1}=M$ and get $q_{2.1}$ and $Z_{2}\left(p_{2.1}, T_{2.1}, q_{2.1}\right)$ using Eq. (14) and Eq. (6) respectively. If $T_{2.1}>N$, then set $T_{2.1}=N$, and obtain $q_{2.1}$ and $Z_{2}\left(p_{2.1}, T_{2.1}, q_{2.1}\right)$ using Eq. (14) and Eq. (6) respectively.

Step 2.2 Set $q_{2.2}=0$. Solve $\frac{\partial Z_{2}(p, T)}{\partial T}=0=\frac{\partial Z_{2}(p, T)}{\partial p}$ to obtain $\left(p_{2.2}, T_{2.2}\right)$. If $M<T_{2.2}<N$, then substitute $T=T_{2.2}$ into Eq. (6) to find $Z_{2}\left(p_{2.2}, T_{2.2}, q_{2.2}\right)$. If $T_{2.2}<M$, then set $T_{2.2}=M$, and obtain $Z_{2}\left(p_{2.2}, T_{2.2}, q_{2.2}\right)$ from Eq. (6). If $T_{2.2}>N$, set $T_{2.2}=N$ and obtain $Z_{2}\left(p_{2.2}, T_{2.2}, q_{2.2}\right)$ by (6).

Step 2.3 Find $\left(p_{2}^{*}, T_{2}^{*}, q_{2}^{*}\right), Z_{2}\left(p_{2}^{*}, T_{2}^{*}, q_{2}^{*}\right)=\max Z_{2}\left(p_{2 . i}^{*}, T_{2 . i}^{*}, q_{2 . i}^{*}\right), i=1,2$.

Step 3 Find the global maximum of $Z_{3}(p, T, q)$ say $\left(p_{3}^{*}, T_{3}^{*}, q_{3}^{*}\right)$ as follows: 
Step 3.1 Set $Q=U$ solve for $\left(p_{3.1}, T_{3.1}\right)$ by solving $\frac{\partial Z_{3}(p, T, q)}{\partial p}=0=\frac{\partial Z_{3}(p, T, q)}{\partial T}$. If $T_{3.1}>N$, then substitute $T=T_{3.1}$ into Eq. (14) and Eq. (7) to obtain $q_{3.1}$ and $Z_{3}\left(p_{3.1}, T_{3.1}, q_{3.1}\right)$. Otherwise, set $T_{3.1}=N$ and find $q_{3.1}$ and $Z_{3}\left(p_{3.1}, T_{3.1}, q_{3.1}\right)$ from Eq. (14) and Eq. (7), respectively.

Step 3.2 Set $q_{3.2}=0$. Solve $\frac{\partial Z_{3}(p, T)}{\partial p}=0=\frac{\partial Z_{3}(p, T)}{\partial T}$ for $\left(p_{3.2}, T_{3.2}\right)$. If $T_{3.2} \geq N$, then obtain $Z_{3}\left(p_{3.2}, T_{3.2}, q_{3.2}\right)$ from Eq. (7). Otherwise, set $T_{3.1}=N$ and obtain $Z_{3}\left(p_{3.2}, T_{3.2}, q_{3.2}\right)$ from Eq. (7).

Step 3.3 Find $\left(p_{3}^{*}, T_{3}^{*}, q_{3}^{*}\right)$ and $Z\left(p_{3}^{*}, T_{3}^{*}, q_{3}^{*}\right)=\max Z_{3}\left(p_{3 . i}^{*}, T_{3 . i}^{*}, q_{3 . i}^{*}\right), i=1,2$.

Step 4 Find $\left(p^{*}, T^{*}, q^{*}\right), Z\left(p^{*}, T^{*}, q^{*}\right)=\max \left\{Z\left(p_{1}^{*}, T_{1}^{*}, q_{1}^{*}\right), Z\left(p_{2}^{*}, T_{2}^{*}, q_{2}^{*}\right), Z\left(p_{3}^{*}, T_{3}^{*}, q_{3}^{*}\right)\right\}$

\section{Numerical example}

Consider, following parametric values in proper units:

$\alpha=10^{6}, \beta=35, \theta=0.05, \eta=1.7, A=200, c=20, h=0.2, I e=12 \%, I c_{1}=13 \%, I c_{2}=21 \%$, $M=17 / 365, N=30 / 365$ and $U=5000$. Using the above algorithm, we obtain the computational results as shown in Tables $1-3$.

\section{Table 1}

Case $1(T \leq M)$

\begin{tabular}{llllll}
\hline Set $Q=U$ & $Q=U=5000$ & $T=0.1328$ & $P=59.20$ & $q=4872.41$ & $Z_{1}=86136.64$ \\
\hline Set $q=0$ & $Q=100.99$ & $T=0.1874$ & $P=59.81$ & $q=0$ & $Z_{1}=82225.07$ \\
\hline
\end{tabular}

\section{Table 2}

Case $2(M<T<N)$

\begin{tabular}{llllll}
\hline Set $Q=U$ & $Q=U=5000$ & $T=0.6288$ & $P=59.27$ & $q=4769.16$ & $Z_{2}=87290.98$ \\
\hline Set $q=0$ & $Q=176.93$ & $T=0.4691$ & $P=60.19$ & $q=0$ & $Z_{2}=83954.56$ \\
\hline
\end{tabular}

\section{Table 3}

Case $3(T \geq N)$

\begin{tabular}{llllll}
\hline Set $Q=U$ & $Q=U=5000$ & $T=0.5658$ & $P=58.04$ & $q=3413.50$ & $Z_{3}=77875.04$ \\
\hline Set $q=0$ & $Q=606.85$ & $T=0.2792$ & $P=60.30$ & $q=0$ & $Z_{3}=85174.15$ \\
\hline
\end{tabular}


Thus, the optimal solution of the problem is $\left(p^{*}, T^{*}, q^{*}\right)=(59.27,0.6288,4769.16)$ and $Z\left(p^{*}, T^{*}, q^{*}\right)=87290.98$

\section{Sensitivity analysis}

In this section, we study the effect of the changes in single parameter at a time (i.e. keeping the other parameters constant as in Example 1) on the optimal solution $\left(p^{*}, T^{*}, q^{*}\right)$ and an objective function is exhibited in Table 4.

\section{Table 4}

Sensitivity analysis

\begin{tabular}{|c|c|c|c|c|c|}
\hline Parameter & Percentage of changes(\%) & & $q^{*}$ & $P^{*}$ & Percentage of profit changes(\%) \\
\hline \multirow{4}{*}{$U$} & -20 & 0.5405 & 3779.9 & 59.37 & -0.7917542 \\
\hline & -10 & 0.5873 & 4274.44 & 59.31 & -0.395871372 \\
\hline & 10 & 0.6663 & 5263.61 & 59.23 & 0.395917196 \\
\hline & 20 & 0.7004 & 5758.21 & 59.19 & 0.791811479 \\
\hline \multirow{4}{*}{$M$} & -20 & 0.5249 & 4769.64 & 59.39 & -1.73816355 \\
\hline & -10 & 0.5785 & 4769.32 & 59.33 & -0.877753921 \\
\hline & 10 & 0.6752 & 4768.74 & 59.22 & 0.871487524 \\
\hline & 20 & 0.7197 & 4768.47 & 59.17 & 1.760491176 \\
\hline \multirow{4}{*}{$N$} & -20 & 0.6288 & 4814.89 & 59.27 & 1.428337727 \\
\hline & -10 & 0.6288 & 4791.93 & 59.27 & 0.633570616 \\
\hline & 10 & 0.6288 & 4747.20 & 59.27 & -0.494759023 \\
\hline & 20 & 0.6288 & 4722.08 & 59.27 & -0.966319773 \\
\hline \multirow{4}{*}{$I_{c 1}$} & -20 & 0.9264 & 4770.94 & 59.64 & 1.248479511 \\
\hline & -10 & 0.7151 & 4769.94 & 59.44 & 0.624463146 \\
\hline & 10 & 0.5807 & 4768.13 & 59.11 & -0.624864104 \\
\hline & 20 & 0.5496 & 4767.26 & 58.94 & -1.250197901 \\
\hline \multirow{4}{*}{ Ie } & -20 & 0.6258 & 4769.05 & 59.28 & -0.055114515 \\
\hline & -10 & 0.6273 & 4769.03 & 59.27 & -0.027562985 \\
\hline & 10 & 0.6303 & 4769.00 & 59.27 & 0.027574441 \\
\hline & 20 & 0.6318 & 4768.98 & 59.27 & 0.055160338 \\
\hline
\end{tabular}

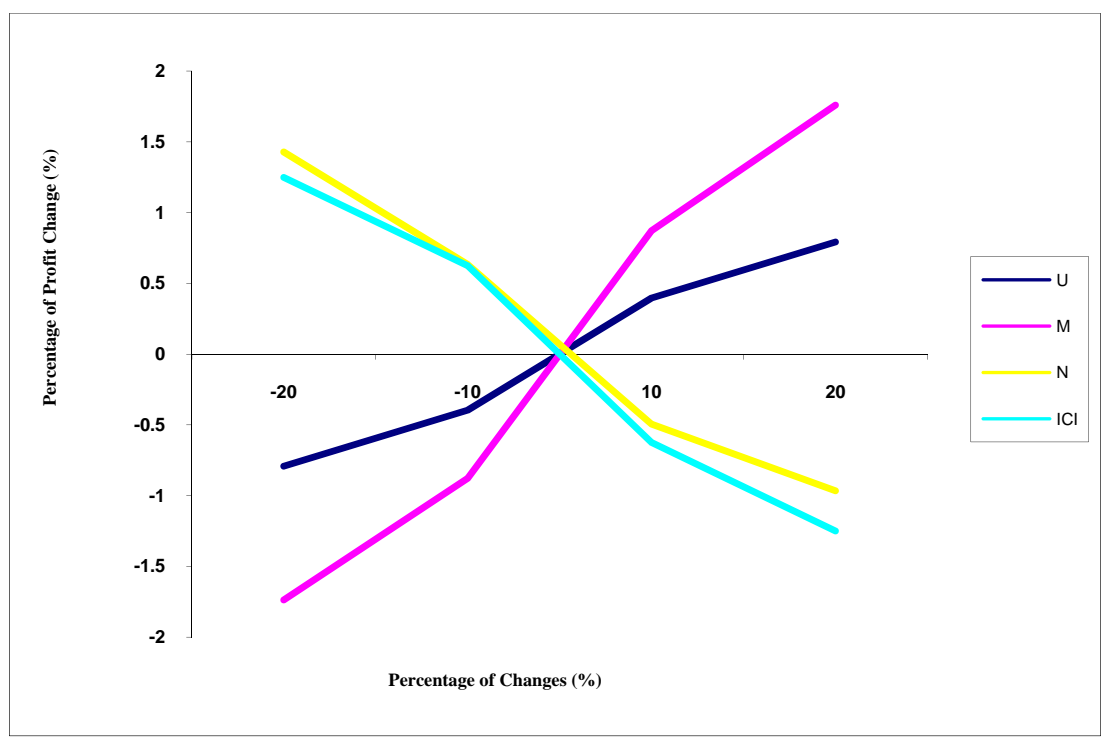

Fig. 1. Sensitivity analysis of the example 
Table 4 reveals that, first, an increase in the maximum inventory level $U$ increases the optimal cycle time $T^{*}$ the optimal order quantity $q^{*}$, and the profit significantly while it also decreases the optimal selling price $p^{*}$. Second, the optimal cycle time, and the profit increase significantly with an increase in the first allowable credit period $M$ while the optimal selling price $p^{*}$ decreases. Third, an increase in the second allowable credit period $N$ results in a decrease in the optimal order quantity $q^{*}$ and the profit. Forth, the optimal selling price and the optimal cycle time are insensitive to changes in $N$, and finally an increase in $I_{c 1}$ lowers all the decision variables and the profit significantly. For details, please see Table 4. Fig. 1 shows the sensitivity analysis of the example when different parameters change.

\section{Conclusion}

When demand is stock-dependent, it is not appropriate to set the terminal condition of inventory level to be zero as considered by Soni and Shah $(2008,2009)$. In this paper, we have extended their model by incorporating the following realistic facts: (1) an ending - inventory to be positive or zero, (2) limited floor space, (3) a profit maximization model, (4) selling price to be a decision variable, and (5) units in inventory deteriorate at a constant rate. In addition, we have also developed an algorithm for the optimal decision policy. Finally, sensitivity analysis has been carried out to investigate critical parameters and provide some managerial insights.

\section{References}

Baker, R.C., \& Urban, T.L. (1988). A deterministic inventory system with an inventory level dependent demand rate. Journal of the Operational Research Society, 39, 823-831.

Chang, C.T., Ouyang, L.Y., \& Teng, J.T. (2003). An EOQ model for deteriorating items under supplier credits linked to ordering quantity. Applied Mathematical Modelling, 27, 983-996.

Chang, C.T., Goyal, S.K., \& Teng, J.T. (2006). On 'An EOQ model for perishable items under stock-dependent selling rate and time-dependent partial backlogging' by Dye and Ouyang, European Journal of Operational Research, 174, 923-929.

Chang C.T., Teng J.T., \& Goyal S.K. (2008). Inventory lot-size models under trade credits: A review. Asia-Pacific Journal of Operational Research, 25, 89-112.

Chang, C.T., Teng, J.T., \& Goyal, S.K. (2010). Optimal replenishment policies for non-instantaneous deteriorating items with stock-dependent demand. International Journal of Production Economics, 123, 62-68.

Datta, T.K. \& Pal, A.K. (1990). A note on an inventory model with inventory level dependent demand rate. Journal of the Operational Research Society, 41, 971-975.

Giri, B.C. \& Chaudhuri, K.S. (1998). Deterministic models of perishable inventory with stockdependent demand rate and nonlinear holding cost. European Journal of Operational Research, 105, 467-474.

Giri, B.C., Pal, S., Goswami, A. \& Chaudhuri, K.S. (1996). An inventory model for deteriorating items with stock-dependent demand rate. European Journal of Operational Research, 95, 604610.

Levin, R.I., McLaughlin, C.P., Lamone, R.P. \& Kottas, J. F. (1972). Productions /Operations Management: Contemporary Policy for Managing Operating Systems, McGraw-Hill, New York, 373.

Mandal, B. N. \& Phaujder, S. (1989). An inventory model for deteriorating items and stockdependent consumption rate. Journal of the Operational Research Society, 40, 483-488. 
Ray, J. \& Chaudhuri, K.S., (1997). An EOQ model with stock-dependent demand, shortage, inflation and time discounting. International Journal of Production Economics, 53, 171-180.

Silver, E.A. \& Peterson, R., (1982). Decision Systems for Inventory Management and Production Planning, $2^{\text {nd }}$ edition, Wiley, New York.

Soni, H., \& Shah, N. H., (2008). Optimal ordering policy for stock-dependent demand under progressive payment scheme. European Journal of Operational Research, 184, 91-100.

Soni, H., \& Shah, N. H. (2009). Ordering policy for stock-dependent demand rate under progressive payment scheme. International Journal of Systems Science, 40, 81-89.

Urban, T. L., (1992). An inventory model with an inventory-level-dependent demand rate and relaxed terminal conditions. Journal of the Operational Research Society, 43, 721-724.

Urban, T. L., (2005). Inventory models with inventory-level-dependent demand: A comprehensive review and unifying theory. European Journal of Operational Research, 163, 792-804. 